\title{
Commentary \\ The Role of Health Promotion in Disease Outbreaks and Health Emergencies
}

\section{Glenn Laverack}

Health Promotion Research, University of Southern Denmark, Niels Bohrs Vej 9, 6700 Esbjerg, Denmark; glaverack@health.sdu.dk

Academic Editor: Kristine Crondahl

Received: 22 December 2016; Accepted: 7 February 2017; Published: 10 February 2017

\begin{abstract}
Health promotion has a key role to play in disease outbreaks and health emergencies because it can offer well-established bottom-up approaches that engage with people to be an active part of a response. International agencies did learn from their earlier mistakes in, for example, the recent Ebola virus outbreak in West Africa, even though an attempt to engage with communities was not initially widely implemented. Many agencies preferred to use pre-packaged approaches which had an emphasis on individual behavior changes and health care delivery. This had a questionable effect because disease outbreaks and health emergencies must actively communicate with and involve people to be successful. Health promotion practice recognizes the value of community capacity-building, participation and empowerment-aspects that are already intrinsic to many health promotion programs. An understanding of how this is achieved in practice will help agencies to find an appropriate way forward to involve and better communicate with communities when the next disease outbreak inevitably occurs.
\end{abstract}

Keywords: disease outbreaks; empowerment; health promotion; communication; community engagement

\section{Introduction}

Over the past 20 years the number of international actors involved in disease outbreak and health emergency responses has dramatically increased. In the aftermath of the 2010 earthquake in Haiti, for example, several hundred international non-governmental organizations were mobilized alongside the United Nations, the government and the private sector, greatly increasing the complexity of the situation. The growing number of such events has placed pressure on the availability of funding opportunities and, at the same time, there has been a realization that the goal of involving communities has not succeeded, yet is crucial to success [1]. The transmission of communicable diseases between countries is also a growing issue in which one country cannot be separated from another because connections between people span national, geographic and cultural borders. For example, the rapid spread of the Ebola virus in West Africa was exasperated by the cross-border movement of people and by an already fragile healthcare system not designed to contain a disease outbreak [2].

An outbreak can refer to an increase, often sudden, in the number of cases of a disease above the endemic level in the population within a restricted geographical area or may extend over a much broader area and may last for a prolonged period of time. A health emergency occurs when the consequences have the potential to overwhelm the capabilities of the health system to contain the problem [3]. Disease outbreaks and health emergencies are closely connected and the term "disease outbreaks" has been used in this commentary to cover both contexts. 


\section{The Role of Health Promotion in Disease Outbreaks}

Health promotion has a key role to play in disease outbreaks because it can offer well-established approaches that can be utilized as part of a response. These are essentially bottom-up approaches that actively involve communities as the way forward and integrate local expertise and civil society networks for the delivery of activities. The role of health promotion includes data collection, communication, community capacity-building and engagement, and rumor and resistance management. In the post-outbreak response, health promotion also has a valuable role in addressing stigma, working with survivors and providing social support to families and communities.

Community engagement is an especially important but underestimated activity that is a crucial step to help others to address the risks that are caused by an outbreak. Communication is also an important approach encompassing health communication and communication for development which are used to promote positive health behaviors. Hygiene promotion campaigns, for example, prevent person-to-person disease transmission by targeting individuals to hand-wash with soap. However, the emphasis on individual responsibility must avoid leading to accusations of 'victim-blaming', making people feel guilty about their state of health even though certain risk factors are outside of their control, for example not having proper quarantine facilities to prevent cross-infection. The guiding principle is to facilitate people to make informed choices to collectively modify their behavior by identifying their needs and then by taking actions to resolve them, such as self-quarantine and disinfection to avoid infection.

The critical point is that disease outbreaks can only be fully addressed by helping people to empower themselves rather than simply trying to change their behavior. The difference is whether or not the approach gives the health promoter the authority to control the situation, for example through setting the agenda. If it does, it is less likely to be empowering. If it facilitates a process of needs assessment, planning and capacity-building toward collective action, it has a much better chance of success. The advantage of empowerment is that it strengthens the whole, the individual, the family group, and the community. Empowerment increases autonomy, personal skills, and gives people the control they need to achieve healthier lives [4].

Health promotion has an important role in the post-outbreak period as it increases awareness about available facilities and promotes the use of services such as vaccination, counseling and welfare initiatives. Health promotion can help to build social support networks for the survivors of an outbreak and to counter stigma and isolation. A number of medical complications have been reported in survivors, for example in those of Ebola and Zika diseases, including eye and neurological problems such as microcephaly and Guillain-Barré syndrome [5]. Health promotion support includes counseling survivors, mobilizing communities to assist with rehabilitation services for people with disabilities, social support through self-help groups and networking of patients dealing with the long-term psychosocial complications.

\section{Conclusions}

Disease outbreak control efforts must actively communicate with and involve people to be more successful. International agencies did not learn from their earlier mistakes in disease outbreaks and attempts to engage with communities using bottom-up approaches were not widely implemented. Many agencies preferred to use pre-packaged and top-down approaches, which have an emphasis on individual behavior changes and service delivery. Commentators have suggested that top-down tactics have had a questionable effect, potentially worsening the epidemic, and contributing to a greater social and economic burden in West Africa [6]. A key concern is whether or not the lessons offered by health promotion have really been learned, or if top-down approaches will continue to dominate the disease outbreak responses of the future. Disease outbreak control is an expanding and new professional area in health promotion that requires a unique set of technical competencies. Health promotion can make an important contribution because it shows us how to enable people to take more control over their lives and health during a disease outbreak. This role can be traditionally carried out by health educators 
and health promoters but also applies to any health workers that are involved in activities such as community engagement, raising awareness, training and counseling. Community capacity-building, participation and empowerment are already intrinsic to a health promotion practice that recognizes the value of a bottom-up approach. This understanding can help agencies to understand an appropriate way forward to involve communities when the next disease outbreak inevitably occurs [2].

Conflicts of Interest: The author declares no conflict of interest.

\section{References}

1. Tellier, S.; Roche, N. Public Health in Humanitarian Action; School of Global Health, University of Copenhagen: Copenhagen, Denmark, 2016.

2. Laverack, G.; Manoncourt, E. Key Experiences of Community Engagement and Social Mobilization in the Ebola Response. Glob. Health Promot. 2016, 23, 79-82. [CrossRef] [PubMed]

3. Nelson, D.; Adger, R.; Brown, K. Adaptation to environmental change: Contributions of a resilience framework. Annu. Rev. Environ. Resour. 2007, 32, 395-419. [CrossRef]

4. Tengland, P. Behaviour change or empowerment: On the ethics of health promotion goals. Health Care Anal. 2016, 24, 24-46. [CrossRef] [PubMed]

5. World Health Organisation. Ebola Situation Rseports; WHO: Geneva, Switzerland, 2016. Available online: http://www.who.int/ebola/situationreports (accessed on 9 August 2016).

6. Institute of Development Studies (IDS). Local Engagement in Ebola Outbreaks and Beyond in Sierra Leone; Report; Practice paper in brief dated 24 February 2015; Institute of Development Studies: Brighton, UK, 2015.

(C) 2017 by the author; licensee MDPI, Basel, Switzerland. This article is an open access article distributed under the terms and conditions of the Creative Commons Attribution (CC BY) license (http://creativecommons.org/licenses/by/4.0/). 